\title{
LAS ACTITUDES ANTE LA MUERTE: TESTIMONIOS EN LA LITERATURA TESTIMONIAL DE LA PRIMERA GUERRA MUNDIAL
}

\section{THE ATTITUDES IN FRONT OF THE DEAD: TESTIMONIES IN THE NOMINAL LITERATURE OF THE FIRST WORLD WAR}

\author{
José Rodrigo Rodríguez López*
}

\author{
Esto es un ataúd, un ataúd móvil. \\ Nos quieren muertos o viviendo en sus mentiras. \\ James Jones. La delgada línea roja.
}

\section{RESUMEN}

Este texto analiza las actitudes ante la muerte en la literatura testimonial de la Primera Guerra Mundial. La finalidad de esto es mostrar de qué manera la muerte como paso a la eternidad, significó dar la vida en aras de una buena causa, por lo que se consideraba una voluntad nacional, con la cual se alcanzaba el recuerdo indeleble de sus compatriotas y el bien morir.

PALABRAS CLAVE: MUERTE * GUERRA * ACTITUDES * LITERATURA * TESTIMONIO

ABSTRACT

This text analyzes the attitudes before in front of the death in the nominal literature of the First World War. The purpose of this work is to show in which way the death like step to the eternity, meant to give the life in altars of a good reason, in the same way it was considered to be a national cause that will to reach the indelible memory of his compatriots and died by love of his owns convictions.

KEYWORDS: DEATH * WAR * ATTITUDES * LITERATURE * TESTIMONY

Coordinación de Ciencias Sociales y Humanidades de la Universidad Autónoma de San Luis Potosí, México. chino_bass_1@hotmail.com 


\section{INTRODUCCIÓN}

El objetivo de este texto es analizar las actitudes ante la muerte en la literatura testimonial de la Primera Guerra Mundial ${ }^{1}$, para lo cual se ha dividido en dos apartados principales. En el primero se realiza un breve estado de la cuestión con el objetivo de delimitar teórica y metodológicamente esta contribución. El segundo apartado justifica el corpus literario elegido, examina las actitudes, los discursos y los ritos antes de la muerte concebidos desde la perspectiva de este texto, como una creencia generalizada entre los miembros de los ejércitos enfrentados, lo cual se basó en el inevitable sacrificio que tuvieron que aportar para cubrir el inmenso costo de la paz, que constituyó la victoria para unos y la derrota para otros.

Algunas de las raíces que dieron forma a la Primera Guerra Mundial de acuerdo con Benedict Anderson (1993), pueden encontrarse en las luchas y las políticas expansionistas llevadas a cabo por las grandes potencias imperialistas de Francia, Gran Bretaña, Alemania, Rusia, Estados Unidos y Japón, los cuales habían iniciado, desde finales del siglo xix, su expansión colonial y su influencia económica, en particular en el continente africano $y$ el sudeste asiático, pues al mismo tiempo que se erguían los imperios marítimos y coloniales de las potencias occidentales, otros más antiguos imperios continentales dinásticos se abatían en el este de Europa. El fondo de los problemas de expansionismo e imperialismo provocó el

$1 \quad$ Hay muchos motivos por los cuales la guerra de 1914-1918 no tuvo precedentes y por los cuales, en la historia humana, fue un suceso completamente novedoso. Guerras anteriores, tales como las revoluciones francesas y napoleónicas, habían sido de mayor duración e implicado igual número de pueblos. Fue el primer conflicto general entre los Estados nacionales altamente organizados del siglo $\mathrm{xx}$, capaces de aprovechar las energías de todos sus ciudadanos o súbditos, de movilizar la capacidad productiva de las industrias pesadas y de utilizar todos los recursos de la tecnología moderna. Desde su inicio pareció probable que semejante guerra resultaría no solo más destructiva de vidas y bienes que cualquier conflagración pasada, sino de mayor alcance, más incalculable y más incontrolable en sus consecuencias. Véase: Thomson, 1970. desmoronamiento de la monarquía dual austrohúngara, el del vasto imperio Otomano y el del inmenso imperio ruso de los Romanoff. Las fuerzas del nacionalismo y del liberalismo que se habían extendido por todo el mundo desde la segunda mitad del siglo xix, apenas empezaban a mostrar su influencia en estos conglomerados, pues la legitimidad fundamental de dichos Estados dinásticos carecía de nacionalidad y de integración multinacional y multiétnica.

A pesar de que guerras como la ruso-japonesa en 1905 o la guerra ítalo-turca en 1912, habían captado la atención del mundo, no habían pasado de ser conflictos focalizados; solo el levantamiento bóxer en China a principios del siglo xx había suscitado cierta parte de la atención de las grandes naciones imperialistas, ya que este conflicto unificó una fuerza única conocida como la alianza de las ocho naciones imperialistas: Japón, Rusia, Gran Bretaña, Francia, Italia, Estados Unidos, Alemania y Austria-Hungría, las cuales en su deseo de restablecer por medio de la fuerza el comercio y su dominio colonial se unieron y derrotaron a las fuerzas chinas. Estas alianzas y amistades sirvieron, en parte, para mantener la paz y el equilibrio europeo. Pero las rivalidades económicas, el deseo de asegurarse los mercados mundiales a cualquier precio, la aspiración del predominio político nacido de una idea nacionalista, el crecimiento inmoderado de armamentos modernos, ejércitos y armadas, los conflictos coloniales, todo esto precipitó el advenimiento de la conflagración mundial.

La idea de nacionalismo que reinaba en esos tiempos contribuyó a un sentimiento colectivo de guerra $y$ deseos de anexión por parte de las principales potencias involucradas: el resentimiento nacional y el deseo de Francia de recuperar los territorios de Alsacia y Lorena, perdidos durante la guerra franco-prusiana; la enemistad entre el opulento imperio austrohúngaro y el creciente nacionalismo de Serbia, esta última protegida de Rusia pretendía anexionarse Bosnia-Herzegovina; la unificación y expansión del imperio alemán y su deseo de ampliar sus dominios y colonias a lo cual se oponían Gran Bretaña y Francia; la aspiración de Italia de anexar a su territorio Trento y 
Trieste y asegurarse el dominio de las islas de Asia Menor; el temor de Rusia ante el poderío siempre creciente de Alemania. Viejos rencores, odios y ambiciones entraron en juego. Las potencias mundiales no se atrevieron a declarar la guerra por cuestiones económicas, aunque de hecho la guerra comercial existía: esperaron un conflicto de fronteras, un incidente político para iniciar la primera conflagración mundial. El pretexto se encontró en los Balcanes "la espoleta de la guerra".

Se puede afirmar que durante la Primera Guerra Mundial, quienes decidieron enlistarse o fueron enlistados para portar el uniforme $y$ el fusil fueron arengados por la idea según cual, era preferible morir defendiendo su país que aceptar las condiciones de la derrota $y$ el sometimiento a las voluntades de potencias extranjeras en una guerra de la cual, muy poco entendían. Esta idea del sacrificio, dio lugar al uso de la violencia como la interlocutora entre los largos años de guerra y la paz, lo que dio como resultado la consagración de la muerte como una actitud cotidiana. Esto se explica porque la movilización para el esfuerzo bélico exigía el compromiso de los ciudadanos para con su nación y tanto la disidencia como la aceptación con dicho patriotismo, en gran medida fueron recompensadas con la muerte debido a que el aspecto militar de la Primera Guerra Mundial pasó a ser un gran gigante disfuncional como cualquier otra gran burocracia, ya que cuando un oficial trató de dar fe a ese nacionalismo, causó la muerte de un pelotón o de un batallón completo el cual fue visto como solo una cifra o números que debieron ser sacrificados en aras de las llamadas "causas nacionales".

Son ilustrativas de la afirmación precedente, las expresiones y los pensamientos de los diferentes soldados que vivieron los rigores de la guerra, la muerte y la desesperación. Por ejemplo, en la novela Sin Novedad en el Frente (2009), el personaje principal suscribe:

Soy joven, tengo veinte años, pero aún no sé nada de la vida, solamente de la desesperación, la muerte, el miedo, y la vana superficialidad impregnada en un abismo de dolor. Veo cómo se pone a las personas unas contra otras, $y$ en silencio, sin saberlo, tontamente, obedientemente e inocentemente se matan unas a otras (Remarque, 2009: 263).

De igual forma, a los muertos se les recordaba siempre vivos en el imaginario colectivo, tal como lo describe Siegfried Sassoon (2003), en la consigna que se hacían los soldados británicos en el frente occidental:

Los muertos en los combates de otoño han sido enterrados someramente en el parapeto, lejos de nuestra Inglaterra, pero su presencia nos inspira a luchar y vengar la sangre derramada (Sassoon, 2003: 123$)^{2}$.

Mientras que Gabriel Chevallier (2009), señala las expresiones evocadoras a la muerte empleadas durante el asalto a las trincheras enemigas:

Los chicos parecen tan impresionados como yo, $y$ todos pegamos un brinco cuando la megafonía lanza una imperiosa arenga "ipreparados para salir, calar bayonetas; vamos!" seguida por el estridente sonido de silbatos, $y$ al final se escucha una voz: "Malditos cobardes", dice el oficial, $y$ el sargento le responde: Nada de cobardes, están endemoniadamente muertos (Chevallier, 2009: 120).

Por otra parte, se aceptaba que para alcanzar esa otra vida que ofrecía la victoria, había que pagar un alto costo en vidas humanas como finalmente ocurrió al terminar las hostilidades bélicas. El martirio, el sacrificio y el dar o quitar la vida llegaron a formar parte

2 Este testimonio se presenta como un detallado relato de la vida durante la Primera Guerra Mundial, especialmente en el frente francés. Su protagonista, George Sherston (álter ego de Sassoon), pasa de ser el soldado patriota y exaltado del principio del libro al furioso antibelicista que arroja su condecoración al río y realiza una protesta pública contra la continuación de enviar más soldados a la muerte. 
de la violencia desatada en los diferentes campos de batalla en Europa, África y Asia a partir del año 1914, puesto que como señala Norman Stone (2008), el primer gran genocidio ocurre en las trincheras, pues los soldados estaban predestinados a perder la vida y se arrogaban el derecho a la violencia, imponían dogmas y combatían a quienes eran sus enemigos, pero ambos bandos compartían un factor común: ser hombres europeos ( $y$ de las colonias europeas en África y Asia) aparecían fragmentados en diversas naciones, las mismas cuyos estados precipitaron su muerte.

Explorar por qué la muerte, como paso a la perennidad, significó dar la vida por su nación, que a su vez tendría bajo su responsabilidad recordar para siempre a sus héroes, fueron creencias que configuraron una actitud de inmolación en la cual era bien visto matar o morir, puesto que el ideal —la defensa de la patria y la inmortalidad-iban más allá del derecho de la vida $y$ al bien morir.

\section{ACERCA DE LA MUERTE}

En el siguiente apartado se realiza una síntesis bibliográfica cuyas contribuciones teóricas esclarecen las creencias ante la muerte, los tipos de discursos y las definiciones para comprender, en el ámbito específico del tema propuesto, por qué las personas lucharon por una idea de lealtad en una guerra que no entendían y durante ese proceso aceptaron la idea de morir.

Estas precisiones conceptuales comprenden las nociones de muerte vivida, muerte sufrida $y$ los discursos sobre la muerte desarrolladas por Michel Vovelle (1985) para referirse a prácticas rituales $y$ discursivas, las cuales serán empleadas en el capítulo segundo. Michelle Vovelle propuso hace ya algunos años que para abordar las actitudes ante la muerte se deben encadenar tres niveles, la muerte sufrida, la muerte vivida y el discurso sobre la muerte. La muerte sufrida es el hecho en bruto de la mortalidad individual $y$ colectiva, cifras $y$ hechos del peso que tiene la mortandad. La muerte vivida, es la red de gestos y ritos que acompañan el recorrido desde la agonía, hacia la tumba y al más allá. Los discursos sobre la muerte son aquellos que se manifiestan en los ritos funerarios, en los momentos de sensibilidad hacia la muerte, sus repeticiones han evolucionado a través del tiempo (Vovelle, 1985).

Sin embargo, las evidencias documentadas consideran que en las áreas donde estuvieron los principales frentes de guerra: el occidental y el oriental se experimentaron tres formas de muerte: la primera, la de aquellos que murieron por defender lo que según ellos era el honor y la defensa de su Nación; otra, la autoestima, pues los victimarios - los propios soldados de infantería - aunque cumplieron con su deber patriótico, siempre consideraron a sus enemigos como sus iguales y esto llevó a algunos de ellos a vivir con arrepentimiento el resto de sus vidas y finalmente, la de estima social, la que llevó a los perdedores a quedar para siempre señalados por las potencias vencedoras como asesinos y criminales de guerra.

Se presenta esta distinción fecunda para pensar los modos en que se produce la asimilación de la muerte, como la culminación de un ciclo de violencia en el que cualquier persona podía ser víctima o victimario, ante lo cual era preferible morir o vivir el martirio de la agonía en las trincheras. Esta precisión, que media entre la definición teórica y la evidencia documental, es más delimitada y menos hipotética.

Asimismo, es importante el acercamiento de Vincent Thomas (1993), quien afirma que la muerte puede ser social cuando una persona deja de pertenecer a un grupo específico, sea por el límite de edad, por la pérdida de funciones mentales $y / o$ físicas, por un acto de destierro o bien, por el proceso de abolición de un recuerdo. Una muerte social sucede cuando no trasciende, no deja huella, cuando alguien resulta que no es muy importante en la sociedad $y$ pronto se olvida porque no ha sido reconocida por su presencia en el mundo terrenal, en caso contrario, el reconocimiento y el prestigio de alguien trascendental, tiene como premio la remembranza posterior para él y su familia (Thomas, 1993).

De acuerdo con este autor, es en la escala de los valores, donde recibe el origen de los discursos y prácticas culturales asociadas a la irremediable pérdida provocada por el fallecimiento 
de una persona, son las reacciones subjetivas ante un hecho biológico, lo que explica los ritos $y$ los discursos ante la ausencia permanente de un miembro de la sociedad cuando este es reconocido por el prestigio $y$ tiende a bien morir. Pero, ¿qué sucede cuando los miembros tuvieron una muerte deshonrosa? ¿Acaso en el más allá se expresan también los valores y perjuicios de la sociedad de los vivos?

Thomas (1993) explica que la muerte social, no significa necesariamente, la pérdida de la vida para verificar su exclusión en la sociedad. El olvido, la jubilación o la reclusión son formas de morir en vida, cuando ya no se es necesario. La muerte socialmente reconocida es el certificado jurídico que refrenda el fallecimiento de una persona. El autor agrega que no solo mueren individuos o familias completas, también mueren culturas $y$ sociedades, $y$ esto se debe a un proceso necesario de cambio que regenera $y$ produce nuevas culturas, perdiéndose la autenticidad debido a la modernización, a la ciencia y a la tecnología, es por ello que los hábitos culturales nativos desaparecen y no existe preocupación alguna por conservarlos por ser considerados obsoletos.

Para Philippe Ariés (1999), la muerte esta revestida de solemnidad, independientemente del itinerario de la persona, su último encuentro con la vida debe ser decoroso: "la dignidad de la muerte exige ante todo que sea reconocida no solo como un estado real, sino como un acontecimiento esencial, un acontecimiento que no está permitido escamotear" (1999: 489).

Philippe Ariés, reconoce la importancia que representa el culto a los seres queridos ya fallecidos, que no solo se limita a mantener su recuerdo vivo en nuestra memoria, se inicia con la construcción de una morada digna para sus cuerpos o cenizas, un lugar parecido al mundo terrenal, porque representa el lugar de encuentro entre los vivos y los muertos (1999). No obstante, la afirmación del autor, cuando además de perseguir el aniquilamiento físico, se persigue borrar de la memoria cualquier vestigio de recuerdo en el imaginario de los vivos, la tumba colectiva anónima, son los lugares en los cuales priva el secreto de muertes mal vividas.
Desde el punto de vista de la bibliografía revisada, conviene detenerse en las precisiones conceptuales empleadas por los autores citados. Es importante apuntar que ninguno de ellos define qué es la muerte, sus apreciaciones se dirigen a explorar el significado que esta adquiere entre los vivos a partir del conjunto de emociones, actitudes y rituales que acompañan al difunto en su última morada. Esto se explica porque es indudable que la muerte física es reconocida como un suceso inexorable mientras que los eventos culturales que se organizan alrededor de ella son por su naturaleza, eternos, puesto que se supone que serán realizados para siempre por los supervivientes. Esto último explica, por qué la muerte adquiere un significado cultural entre los vivos, debido a que las prácticas culturales asociadas a ella, dan origen a un conjunto de significados que hacen imperecedera en la memoria, a aquél o aquélla que ofrendó su vida, para el caso que se ocupa, en aras de un futuro promisorio repleto de bienestar común (Urrego y Carrillo, 2012).

La Primera Guerra Mundial fue el primer conflicto general entre los Estados nacionales altamente organizados del siglo xx. Se trata también, como señala Eric Hobsbawm (2007), del primer conflicto bélico que en escala suficiente dislocó la economía mundial que durante el siglo anterior, se había entretejido tan reaciamente. Es la primera de las grandes guerras en la historia del siglo xx en que hubo tanta disparidad entre sus efectos y logros, así como en las intenciones y propósitos confesados de los que primero se lanzaron a esta. Pues, a pesar de que años antes se habían librado algunas guerras tanto en el continente europeo como en el asiático, ninguna había recibido el calificativo de "mundial". La "Gran Guerra" (como posteriormente se le llamó), fue el primer conflicto armado que marcó a toda la población mundial de ese entonces: en sus campos de batalla miles de seres humanos perdieron la vida en aras de poner fin a la "guerra que acabaría con todas las guerras". Se lucho desde los campos de batalla de Europa hasta lo largo del Atlántico, las costas de África y Asia. Fue una guerra que cambió el sentido y la visión de la guerra misma. 
Fue en este contexto de lucha impulsada por los países de la llamada Triple Entente: Francia, Gran Bretaña y Rusia, así como de su contraparte, los Imperios Centrales: Alemania, Austria-Hungría y Turquía, que se dio el entorno en el cual surgió la violencia generalizada y derivado de ella, un conjunto de actitudes y rituales alrededor de la muerte que aseguraban la vida eterna, en tanto aquella fuese entregada al esfuerzo de la guerra (Hobsbawm, 1998), de lo contrario, el olvido y la indiferencia, fueron la característica de los discursos mortuorios entre los actores armados.

En un principio, la guerra de posiciones, la cual los alemanes consideraban la estrategia más efectiva para vencer a Francia y así marchar sobre Rusia, llegó a un estancamiento a finales de 1915. A medida que la Primera Guerra Mundial se convirtió en una guerra de trincheras a finales de 1914, se hizo evidente que la victoria solo podría alcanzarse con agotar al bando contrario o de hacer tan elevado el coste de continuar la guerra que la paz se volvería esencial. Los soldados alemanes y franco-británicos se vieron estancados en un frente de trincheras que se extendía por todo el frente occidental en Francia y Bélgica. A partir de 1915, ambos bandos se enfrentaron en una masacre que duró hasta el final de la guerra. En esos años se vio el nacimiento de una de las más aterradoras y mortales armas de la guerra: el gas letal y las minas explosivas, así como de una nueva enfermedad: el trauma de guerra, producido por la "experiencia de las trincheras", donde los soldados de infantería se veían expuestos a saltar de la trinchera y a bayoneta calada, presentar combate frontal en una tierra de nadie expuestos al fuego de las ametralladoras, así como, al fuego de la artillería enemiga. Cientos de miles de soldados murieron inútilmente en este tipo de combates como más tarde lo demostrarían las duras batallas de Verdún o la batalla del Somme, las cuales reclamaron un gran derramamiento de sangre por ambos bandos.

El estudio de las actitudes ante la muerte, en la Primera Guerra Mundial, debe considerar que la violencia fue la verdadera característica de la relación que existió entre los países beligerantes. La muerte y la violencia llegaron a ser parte de la vida cotidiana, a servir de marco para las relaciones interpersonales, particularmente en aquellas regiones del mundo en las cuales el enfrentamiento armado como se menciona en las líneas anteriores, alcanzó sus más altos índices de exacerbación.

Finalmente, quisiera responder a la interrogante ¿por qué reflexionar sobre la muerte? Tal y como afirma Vélez Zapata (2006), quien ha muerto no se hará más preguntas mientras que las interpelaciones de los supervivientes no se harán esperar. Pensar en la muerte, conduce a reflexionar sobre la vida, a pensarse $y$ a pensar sobre el otro, particularmente cuando se proviene de sociedades en las que la vida perdió valor como un derecho inherente al ser humano. Describir los discursos ante la muerte podría sugerir indicios sobre cómo la cultura forjada en condiciones de guerra, contribuyó a moldear un ideal según el cual, era mejor morir bajo la irracionalidad de la violencia que vivir en paz.

\section{MORIR EN LOS TESTIMONIOS}

Después de analizar estas precisiones conceptuales, es necesario exponer cuál es el corpus literario en el cual se basará el presente trabajo. El testimonio de acuerdo a José Domingo Carillo "es un género literario que cumple una función ideológica más que estética, que busca denunciar las condiciones de injusticia, opresión y violencia que experimentan las clases bajas" (2013:88).

Sin embargo, no todos los testimonios consignados y revisados para este trabajo provienen de individuos de las clases bajas, sino de aquellos que en su momento de retiro o en la vida civil, abrieron $y$ decidieron plasmar sus experiencias vividas en combate como una forma de estimular su memoria y así luchar contra el olvido. En esta geografía del testimonio, los textos que fueron elegidos para la realización de este trabajo, fueron seleccionados por los diferentes significados de las experiencias vividas por sus autores $y$ el papel que jugaron en el desarrollo de los conflictos armados (Rodríguez, 2014).

Este trabajo se basó en testimonios publicados o inéditos de ex soldados de algunos de los ejércitos enfrentados durante la contienda, 
tales como, Tempestades de Acero del alemán Ernst Jünger, quien fue soldado y oficial alemán, luchó en el frente occidental donde fue herido catorce veces $y$ fue uno de los pocos en ser condecorado con la medalla Pour le Mérite ${ }^{3}$. Es de utilidad el texto El fuego, diario de una escuadra de Henri Barbusse, quien fuera alférez del ejército francés. Se utiliza también, el texto de Peter Englund, La belleza y el dolor de batalla, en donde el autor recopila los testimonios, diarios y cartas de veinte personas que vivieron a su manera, los rigores de la guerra, la muerte y la desesperación. Por último, el libro Company $K$ de William March, quien sirvió con el $5^{\circ}$ regimiento de la $1^{\text {a }}$ División de Marines.

\section{MORIR EN LA GUERRA}

El libro Tempestades de Acero publicado por primera vez de modo privado por su autor Ernst Jünger en 1920, es uno de los primeros testimonios de la guerra de trincheras, posteriormente fue modificado varias ocasiones (Jünger, 1998). El libro es, siguiendo a Hayden White (1992), una estructura verbal en forma de discurso de prosa narrativa que combina datos etnográficos de las zonas francesas donde estuvo movilizado, las cuales fueron el marco geográfico del frente occidental, hábitos $y$ costumbres de los soldados de primera línea, conceptos del arte de la guerra que describen la organización militar, así como, la vida cotidiana de los soldados alemanes $y$ de sus enemigos franco-británicos, las marchas, los campamentos y las formas de acción directa emprendidas en las trincheras para confrontar a los ejércitos enemigos e incluye, un conjunto de acontecimientos ordenados cronológicamente que supuestamente ocurrieron puesto que están narrados desde su experiencia y como los recuerda para contarlos.

$3 \quad$ Esta fue la máxima condecoración alemana durante la Primera Guerra Mundial. Entre los hombres que la recibieron se encuentran Manfred Von Richthofen (el Barón Rojo), Erwin Rommel y Hermann Göring estos dos últimos mariscales del Tercer Reich Alemán durante la Segunda Guerra Mundial.
La obra de Jünger tiene una estructura de naturaleza nacionalista debido a que el hecho narrado - su experiencia en la guerra, así como, su alabanza hacia esta - fueron considerados un referente para la dignidad nacional alemana. White (1992), señala que el pasado se ficcionaliza de acuerdo al lugar que ocupa el evento descrito, es decir, al inicio, en medio o al final de una narrativa histórica. Jünger ordena los hechos de acuerdo a una visión patriótica de la historia, parte del supuesto de un conocimiento, debido a que la emergencia de la movilización nacional por la guerra son los orígenes de un espíritu y valor que solo el yunque de la guerra puede forjar. La forma en la que asume la trama es romántica, en tanto simboliza la trascendencia del individuo y la acción de este en la batalla, es un drama de la guerra más preocupado por las acciones lúcidas que por las reacciones que esta generó: muerte, destrucción y violencia 4 .

No obstante, las cualidades que posee el discurso histórico-testimonial, según Hayden White es que la ficción ocupa un lugar importante en la interpretación del pasado, no porque se nieguen los hechos sucedidos sino porque cada autor los narra desde su propia experiencia matizada con el pensamiento que caracterizó a los bandos enfrentados. La importancia de reconstruir algunas de las expresiones culturales que ofrece la literatura testimonial es que admite establecer un diálogo entre las distintas narrativas sobre la guerra y plantearle a esa polémica, una agenda de nuevas preguntas que acerque a ponderar el peso del testimonio y el papel desempeñado en los años del conflicto ${ }^{5}$.

Por contraste, el libro El fuego, diario de una escuadra (Barbusse, 2009), describe a un socialista enemigo acérrimo del militarismo que se alistó como soldado raso. A pesar de su aversión al conflicto, él pensaba que luchaba en "una guerra que pondría fin a todas las

$4 \quad$ Esta apreciación y crítica historiográfica de las obras reseñadas se basa en el texto de White (1992). Véase la introducción.

5 Una crítica a la postura de Hayden White que establece las diferencias entre la narrativa histórica y la narrativa literaria se encuentra en Molina Jiménez (2006). 
guerras". Publicado en plena guerra, el libro contiene una prosa muy angustiante, en sus páginas desfila ante nosotros la vida de un pelotón de infantería, la lucha feroz de las trincheras, los bombardeos que pulverizan los cuerpos y devastan las almas:

Los compañeros van cayendo, uno a uno, o varios a la vez, heridos, muertos, desaparecidos, tragados por el barro de las trincheras, convertidos muchas veces en un espantoso elemento del paisaje. Las condiciones son infrahumanas, pero los soldados luchan valientemente, a pesar de todo, con un heroísmo grave, silencioso, humilde, pero no menos grande (Barbusse, 2009).

En las páginas del libro se subraya la perseverancia e importancia de la moral francesa ante la imponente ofensiva alemana como un factor que estimuló el sentimiento de la esperanza y resistencia de aquellos hombres encargados de defender su país, en contra de un enemigo que estaba decidido a acabarlos moral y físicamente. Después de 18 meses de acción, Henri Barbusse dejó el frente.

Por otra parte, en la narración del libro de Peter Englund, se describe también cuando la muerte se asoma dentro de los propios ejércitos, donde el ajusticiamiento de los desertores era la forma a través de la cual se castigó a los que pretendieron abandonar su conscripción. Tal y como lo narra Englund:

He ahí el primer condenado. Un llanto sin lágrimas, un estertor de la garganta oprimida. Ni una palabra. Ojos que ya no expresan nada. En el rostro sólo se percibe el vago terror de la bestia que va al matadero. Llevado hasta un abeto no se tiene en pie, se desploma. Hay que atarlo al tronco con un cable telefónico. El capellán, lívido, le abraza. Mientras tanto el pelotón forma dos filas. Son los de la primera fila los que van a disparar. El edecán del regimiento ya ha dado las explicaciones: "Yo hago una señal con la mano. A continuación fuego" (2008: 370-478).
La redención de los soldados se obtiene después del fusilamiento del disidente, cuando se ha cumplido con la condena de muerte regulada por los mandos superiores del ejército en cuestión. La evaluación que hace el autor de quienes abandonaron sus respectivos ejércitos por heridas o por muerte a diferencia de quienes la traicionaron es benevolente. Ofrecer el testimonio cumple la función del olvido a quienes el autor considera que por su grado de compromiso con la guerra, su historia de vida debe pasar a la posteridad, aún y cuando para las nuevas generaciones de ciudadanos, los episodios de la Primera Guerra Mundial y los que tomaron parte en ella sean desconocidos. La nostalgia que despierta en los que conocieron de cerca los acontecimientos narrados, pretende ser una lección moral para quienes conocen por referencias los años de la guerra.

Es como señala Serena Nanda (1987), la muerte es la etapa en la cual se intenta sustraer al finado del aislamiento producido por la defunción y pretende de manera simbólica incorporarlo a un nuevo status, el de encontrarse en el más allá con sus camaradas de lucha quienes según la autora, reinan en el imaginario colectivo, residencia última de aquellos que dieron su vida por su nación. Morir o matar no fue una práctica ajena para los contendientes que se enfrentaron a lo largo de cuatro años.

Los Estados Unidos habían entrado a la guerra el 4 de abril de 1917, a principios del siguiente año, las tropas americanas en Europa llegaban a los 750000 hombres movilizados (Thomson, 1970). La batalla de Belleau Wood a principios de 1918, fue uno de los momentos más cruciales para las tropas norteamericanas (Merrow, Starace y Von Hassell, 2014). Esta batalla fue el bautismo de fuego de los marines. William March estuvo entre los marines que tomaron parte en ella. En su libro Company $K$ (1989), los muertos que pueblan sus páginas no lo son como consecuencia de nobles sacrificios; sus muertes forman parte de un brutal escenario, marcado por la crueldad y la degradación. En este sentido, se está ante un libro duro en el que no se encubre ni se disfraza el horror de la guerra. 
En este texto, dividido en estampas individuales, las cuales son narradas por cada uno de los soldados de la compañía a la que el autor del libro perteneció durante los cruentos días de guerra donde se pueden observar los horrores de esta: asesinatos, fusilamientos, ejecuciones sumarias, bombardeos, así como, el regreso a casa y la posterior vida y reinserción a la sociedad civil. Cada estampa ocupa poco más de una página y se pasa de un escenario a otro, de una batalla a otra, de un paisaje a otro. No existe un argumento único, el recuerdo de la experiencia en la guerra queda grabado en la memoria por el esfuerzo que el autor dedicó a la construcción de las vivencias de toda su compañía. Muchos de los testimonios son narrados por personajes que se encuentran en situaciones extremas, cerca de la muerte o después de alguna escaramuza con el enemigo, o en los asaltos a las trincheras enemigas:

El sargento Tietjen estaba conmigo el día que ocupamos el nido de ametralladoras en el bosque de Veuilly. Descubrimos que había muerto toda la banda, salvo un hombre corpulento $y$ barbudo que estaba malherido. Justo cuando nos aproximábamos, el hombre metió la mano en el interior de su abrigo y hurgó en el bolsillo. Creyendo que iba a lanzarnos una granada, descargué la pistola contra él. Su brazo se deslizó del interior del abrigo con un movimiento brusco e irregular y la palma de su mano se posó durante un instante en sus labios. La sangre que le llenó la garganta empezaba a asfixiarlo y soltó un suspiro ahogado. Los ojos se le pusieron en blanco y se le abrió la boca. Me acerqué y le abrí la mano para ver qué sostenía. Era una foto de una niña alemana. Tenía la cara redonda y pecosa $y$ sus cabellos ensortijados especialmente para la ocasión le caían sobre los hombros. -Debe de ser su hija- dijo el sargento Tietjen. Pasé aquella noche en vela pensando en ese soldado alemán. Me revolví en la cama hasta que, hacia el amanecer, Tietjen vino a tenderse a mi lado. - No sirve de nada sentirse culpable, compañero- me consoló. Cualquiera hubiese creído que iba a lanzar una granada (March, 1989: 141).

La narración también describe cuando la muerte pone en duda las acciones de la guerra, donde el recurso de la violencia adquiere aires de castigo. Los fusilamientos fueron la forma a través de la cual se castigó a los que pretendieron traicionar a su patria, pero en este caso, March relata la manera inconsciente de la ejecución a sangre fría de nueve prisioneros de guerra alemanes. En ese sentido, el libro de March (1989) describe como los personajes no tratan de demostrar nada. Son las víctimas de las "causas nacionales", ellos no tienen ninguna opción. Ellos se encuentran en una lucha por la supervivencia constantemente embrutecida y brutalizada por la maldición de guerra. Las referencias a los paisajes y el escenario del fragor de la batalla describen un bosque repleto de muerte, que fue el marco para la ejecución de los individuos juzgados por sus propios enemigos quienes contaban - según ellos- con un decálogo de conducta que estipulaba la pena de muerte para aquellos que cayeran en sus manos como prisioneros de guerra y que por sus acciones pasadas, debían morir.

El texto no señala con precisión dónde fueron enterrados los cadáveres de los prisioneros puesto que una muerte deshonrosa no ameritaba el recuerdo de su entierro. Es significativo que la muerte derivada de este acto es, bajo la mirada de March, una forma de morir que se aleja del paradigma del deber del soldado que debe en todo caso, respetar las vidas de los que se consideran "prisioneros de guerra". En este caso, precisa que los huesos enterrados bajo la sombra de grandes robles característicos de la región encarnan, bajo la mirada del autor, el renacimiento de aquellos que no contaban con armas para defenderse y que cayeron por las balas de su fusil y los de sus compañeros. March considera que los fusilados y los caídos en esta batalla poseen al igual que los vivos, la característica de expresar emociones como la felicidad $y$ la muerte significa, a manera de ejemplo para los vivos, que existe la posibilidad de experimentar el goce en el más allá, que 
es posible deleitarse a pesar de haber muerto en las más horribles circunstancias. Habría que añadir que esas formas de morir fueron ironías de la vida y por esa razón, los frutos de los árboles constituyen la metáfora de la nueva existencia que se espera sembrar a partir de la resurrección de los muertos.

March concluye su relato cuando, días antes del armisticio, el personaje principal se encuentra con un soldado alemán que descansa bajo un árbol, ambos enemigos se encuentran frente a frente $y$ el soldado americano clava su bayoneta en el cuello del soldado alemán, una vez muerto este, el soldado norteamericano toma un anillo de la mano muerta de su enemigo y a su vez piensa en la vida que ha quitado:

La figura del alemán se mueve. Me estremezco y la miro. Mis ojos se quedan incrustados en ella. Era un hombre con bigote $y$ ahora está tendido allí con la garganta sangrándole. "Ha muerto me digo". Lo miro $y$ veo su juventud, tan similar a la mía. No quería matarte - le digo- pero sé que tú lo hubieras hecho, por eso tuve que apuñalarte. Ahora sé que no eras más que un joven como yo y que tal vez pudimos haber sido amigos, pero estamos haciendo lo que nos dijeron que teníamos que hacer: matar o morir $y$ por eso yo he tenido que matarte (March, 1989: 220).

Momentos después, la angustia lo hace presa $y$ termina por arrojar el anillo sustraído al suelo, pues de esta manera busca borrar toda conexión que lo relacione con la muerte que acaba de dar a su enemigo. Sin embargo, no podría olvidar jamás el rostro de aquel alemán, seguiría siempre en su mente. De esta manera, March aunque siendo un veterano condecorado, condena la moralidad al patriotismo y muestra un escenario dantesco donde solo existe una delgada línea roja ${ }^{6}$ que separa a los soldados del

$6 \quad$ Esta referencia puede ser analizada en el texto de James Jones sobre una compañía del ejército norteamericano durante la batalla de Guadalcanal en la Segunda Guerra Mundial y los efectos morales que sufren los soldados americanos. Véase: Jones, 2000: 29 . heroísmo y el deber, de la locura de la guerra o la muerte $y$ donde estos no se identifican con la idea de "heroísmo", sino que son las víctimas de las grandes causas nacionales en las cuales no hay opción alguna.

\section{CONCLUSIÓN}

Morir en la guerra desliga a la muerte de todo significado oficial y cultural, puesto que el contexto bélico no admite la expresión y realización de ritos funerarios, a su vez, el soldado fallece en soledad, alejado de sus afectos familiares, su cuerpo es reconocido a la distancia por aquellos quienes se encuentran en el mismo contexto bélico como amigos, compañeros y comandantes militares.

La muerte en esas circunstancias impidió cualquier ritualidad conocida tales como los velorios ornamentados con coronas de flores, la preservación del luto entre los deudos, el paseo del cortejo fúnebre para hacer partícipe a la comunidad de la pena que embargaba a los dolientes $y$ las visitas a los cementerios, puesto que la guerra no permitía esas consideraciones, por eso la exigencia de preservar en la memoria a los caídos en combate. A casi cien años del inicio de las hostilidades, hoy es usual ver en Francia los distintos cementerios con sus miles de lápidas en las que el recuerdo, los nombres y la fecha en que murieron sus ocupantes refrenda el compromiso de no olvidar.

Los ritos como expresiones simbólicas no son recurrentes en las páginas de los testimonios consultados. Esto se explica porque en medio de los riesgos y peligros que corrían los soldados, les era imposible realizar cualquier expresión de pérdida ante uno de los caídos en combate. Generalmente, se dejaba el cuerpo de los fallecidos ante la imposibilidad de llevarlos consigo. A pesar de esas irrefutables condiciones de vida es indiscutible también que fueron establecidas algunas creencias en torno a cómo debería morir aquél que había decidido pelear por su país en una guerra como esta.

Fue imprescindible entregar la vida por las causas nacionales, solamente de esa forma el recuerdo imperecedero estuvo garantizado, cualquier otra forma de morir fue desdeñada 
y enviada al olvido. La vida entonces ocupó un segundo lugar puesto que fue la muerte la etapa que garantizaba el recuerdo permanente entre los vivos. El duro camino hacia la paz significó destinar muchas vidas para alcanzar el triunfo o la derrota, sin embargo, ha sido el olvido de los caídos y de la guerra misma lo que deparó el presente.

\section{BIBLIOGRAFÍA}

LIBROS

Anderson, Benedict. Comunidades imaginadas. Reflexiones sobre el origen y la difusión del nacionalismo. México: Fondo de Cultura Económica, 1993.

Ariés, Philippe. El hombre ante la muerte. Madrid, España: Taurus, 1999.

Barbusse, Henri. El fuego (diario de una escuadra). Barcelona, España: Editorial Montesinos, 2009.

Chevallier, Gabriel. El miedo. Barcelona: Editorial Acantilado, 2009.

Englund, Peter. La belleza y el dolor de la batalla. La Primera Guerra Mundial en 227 fragmentos. Barcelona: Roca Editorial, 2008.

Hobsbawm, Eric. Historia del Siglo XX. Madrid: Editorial Crítica, 1998.

Hobsbawm, Eric. La era del imperio 1875-1914. Madrid: Editorial Crítica, 2007.

Jones, James. La delgada línea roja. Barcelona: Ediciones B, 2000.

Jünger, Ernst. Tempestades de acero. Barcelona: Editorial Tusquets, 1998.

Malavassi Aguilar, Ana Paulina (compiladora). Historia: ¿Ciencia, disciplina social o práctica literaria? Costa Rica: Editorial de la Universidad de Costa Rica, 2006.

March, William. Company K. Alabama: University of Alabama Press, 1989.

Nanda, Serena. Antropología cultural. Adaptaciones socioculturales. México: Grupo Editorial Iberoamérica, 1987.

Remarque, Erich M. Sin novedad en el frente. México: Editorial Tomo, 2009.
Sassoon, Siegfried. Memorias de un oficial de infantería. Madrid: Editorial Turner. 2003.

Stone, Norman. Breve historia de la Primera Guerra Mundial. Barcelona: Editorial Ariel, 2008.

Thomas, Vincent L (1975). Antropología de la muerte. Edición en español. Marcos Lara (Traductor). México: Fondo de Cultura Económica, 1993.

Thomson, David. "La Primera Guerra Mundial, 1914-1918". Historia mundial de 1914 a 1968. México: Fondo de Cultura Económica, 1970.

Urrego, Miguel Ángel y Carrillo, José Domingo (editores). Etnia, género y case en el discurso y la práctica de las izquierdas en América Latina. México: Universidad Michoacana de San Nicolás de HidalgoUniversidad Autónoma de San Luis Potosí, 2012.

Vovelle, Michel. Ideologías y mentalidades. Barcelona: Editorial Ariel, 1985.

White, Hayden. Metahistoria. La imaginación histórica en la Europa del siglo XIX. México: Fondo de Cultura Económica, 1992.

\section{PUBLICACIONES PERIÓDICAS}

Carrillo Padilla, José Domingo. "El amor en tiempos de guerra: afectos $y$ desafectos en la literatura testimonial centroamericana”. Revista Latinoamericana de Estudios sobre Cuerpos, Emociones y Sociedad 11. Argentina, abril-julio, 2013.

Merrow, Alexander; Starace, Gregory y Von Hassell, Agostino. "Belleau Wood. The Unknown German Perspective". Marine Corps Gazette 11 (92). Marine Corps Association and Foundation, noviembre, 2008.

Molina Jiménez, Iván. "Narrativa histórica y narrativa literaria". Historia: ¿Ciencia, disciplina social o práctica literaria? Ana Paulina Malavassi Aguilar (compiladora). Costa Rica, Editorial de la Universidad de Costa Rica, 2006: 3-11. 
Vélez Zapata, Claudia Patricia, "Hacia una humanización de la empresa funeraria". Pensamiento y Gestión 21. Colombia. Universidad del Norte, 2006: 93-113.
TESIS

Rodríguez López, José Rodrigo. "La batalla por Centroamérica y México: Rebeldes, fuerzas armadas y crimen organizado". [Tesis de Licenciatura en Historia]. México: Universidad Autónoma de San Luis Potosí, 2014.

Fecha de ingreso: 27/05/2014 Fecha de aprobación: 28/08/2014 